\title{
Expanding Clinical Practice with Complementary and Integrative Health, such as Tai Chi, as Therapeutic Interventions
}

\author{
Connor A. Burton, LAT, ATC
}

Indiana State University, Terre Haute, IN

\begin{abstract}
Key Phrases
Therapeutic exercise, emotional wellness, mental health, tai chi

Correspondence

Connor Burton, Indiana State University, 567 N. 5th Street, Terre Haute, IN 47809.

E-mail: cburton24@sycamores.indstate.edu

Twitter: @cburt105

Full Citation

Burton CA. Expanding Clinical Practice with Complementary and Integrative Health, such as Tai Chi, as Therapeutic Interventions. Clin Pract Athl Train. 2018;1(2):32-36. https://doi.org/10.31622/2018/0002.5.1
\end{abstract}

Submitted: September 1, 2018 Accepted: October 23, 2018

\section{COMMENTARY}

$T_{\text {he }}$ he National Institutes of Health (NIH) define complementary and integrative health $(\mathrm{ClH})$ as "those health care practices not currently considered an integral part of conventional medicine." When an intervention is used in addition to conventional care, it is deemed as complementary medicine. Integrative medicine are those interventions that are used in place of conventional care. ${ }^{1}$ Across the general public, the utilization of $\mathrm{ClH}$ in Western society is growing. A 2012 study of nearly 89,000 Americans indicated that $33.2 \%$ were utilizing $\mathrm{ClH} .{ }^{2}$ Within this study, various reasons for utilizing $\mathrm{ClH}$ included health/wellness improvement, treatment for symptoms related to disease, or to improve side effects from modern medicine. ${ }^{2}$ Some Western health care providers have brought $\mathrm{ClH}$ into their practice, whether it be direct incorporation or referral to another qualified provider. Some of these interventions include chiropractic services, massage therapy, relaxation techniques, yoga and tai chi.' Although $\mathrm{ClH}$ continues to grow in Western society as a whole, the utilization of $\mathrm{ClH}$

Copyright $\left({ }^{\circ}\right.$ by Indiana State University All rights reserved. ISSN Online 2577-8188 in modern health care does not follow a similar trend. In order to provide patients with optimal care and satisfactory outcomes, it is crucial to consider all potential interventions when developing a patient-centered plan of care. Acting as the first point of care for the majority of our patient populations, athletic trainers can talk with patients about these unique interventions. In so doing, we play an integral role in starting a movement of holistic health care which provides patients which more options to meet their goals and needs.

\section{What is Tai Chi and how is it implemented into practice?}

There is a strong body of literature supporting the use of tai chi as an intervention for the mental health of young, physically active individuals. ${ }^{3-5}$ Tai chi is a form of martial art and mind-body exercise which originated in China. ${ }^{5}$ This technique is commonly described as combining slow-paced, precise, and constant functional movements with controlled breathing. ${ }^{3-5}$ Tai chi can be implemented into clinical practice through one-onone patient care with goals of addressing specific conditions. Due to the uniqueness of athletic training as a health care profession, tai chi can also be implemented into clinical practice in group intervention sessions. Two examples of this implementation could be facilitation of proper breathing during movement for endurance athletes or promotion of positive mental health. The literature supports the use of tai chi for both orthopedic (balance, agility, postural control, lower extremity strength, ${ }^{3}$ cardiovascular and respiratory function, 7 and pain reduction ${ }^{5}$ ) and mental health (anxiety, 4,5 depression, 4,5 selfesteem, ${ }^{5}$ and $\operatorname{mood} .5$ ). Across the literature, improvement of outcomes were found regardless of the duration (15 to 60 minute sessions), 
frequency of sessions (once per week to daily) and length of patient enrollment in the program (3 to 12 week intervention).

As noted, tai chi can serve as an intervention to address causative factors related to mental health, as well as functional limitations. As a clinician, it is important to understand how a technique can be an effective option in patient care. Moreover, when aiming to provide patient centered care, it is equally important to educate the patient regarding how each available technique can be an effective component of the patient plan of care. For tai chi, the emphasis of the intervention is placed on incorporating relaxation and deep breathing into functional movements. ${ }^{3-5}$ A visual aid of what a tai chi intervention could look like is detailed in Table 1.
This table details notes for the clinician developing and implementing the intervention (left column) in addition to patient education and queves for appropriate integration of breathing with functional movement (right column).

\section{Indications and Considerations for Implementing Tai Chi}

Similar to each therapeutic intervention a clinician uses in clinical practice, it is important to understand the indications, contraindications, and considerations for a technique prior to implementing the technique into a plan of care. Like general physical activity there is an adherent risk of injury which must be acknowledged when performing tai chi. Individuals who have health conditions which require consultation with a

Table 1: Phase progression of diaphragmatic breathing with basic and advanced movements.

\begin{tabular}{|c|c|}
\hline Phase & Concepts for Clinician \\
\hline Diaphragmatic & Hand placement above/below umbilicus \\
\hline Breathing & $\begin{array}{l}\text { Patient should begin diaphragmatic } \\
\text { breathing. Time spent practicing } \\
\text { dependent on dysfunction }\end{array}$ \\
\hline & $\begin{array}{l}\text { Correct any shoulder elevation and rib } \\
\text { expansion during breathing }\end{array}$ \\
\hline & $\begin{array}{l}\text { Progress patient appropriately } \\
\text { supine } \rightarrow \text { sitting } \rightarrow \text { standing }\end{array}$ \\
\hline
\end{tabular}

Functional Patient continues diaphragmatic with Movement basic movements (Single leg squat, arm with Breathing elevation) Maintain proper breathing from phase one with movement. Ensure abdomen is moving with inhalations Progress patient to advanced functional movement when breathing is controlled and routine Examples of Cueing

"Please find a position that is comfortable for you." (standing, seated, or supine) "Please place one hand on your stomach and one hand on your stomach below your belly button."

"Breathe in through your nose so that you feel your stomach expand under your hand. Breathe out through your nose so that you feel your stomach shrink under your hands."

"Starting in a standing position with feet shoulder width apart, breathe in as you raise your arms straight out in front of you." "Breathe out as you squat down and lower your arms to your side at the same time." "Breathe in as you rise up out of the squat and raise your hands straight in front of you." "Continue to focus on breathing through your belly and not raising your shoulders up or expanding your chest when breathing."

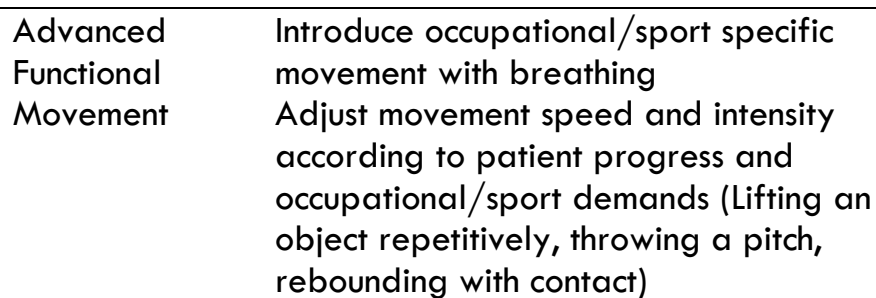

"Breathe in as you properly squat down to pick up this weighted object and breathe out as you pick the object up."

"Breathe in as you enter your wind-up phase and breathe out as you progress through your early cocking and follow-through phases of throwing." 
physician prior to partaking in physical activity (e.g. heart condition, severe osteoporosis) should take precaution. Additionally, individuals with an orthopedic injury that requires modifications to activities of daily living or physical activity should take precaution and consult with their health care provider.

To obtain the greatest results, the difficulty of the tai chi exercises should be tailored to the patient's experience level with the intervention and fitness. ${ }^{6}$ Tai chi can be utilized for any patient who is physically active. For patients who only complete walking and activities of daily living, a clinician can develop a program which revolves around foundational movements, such as mini squats with synchronous arm swings or controlled lunges. For patients who partake in a high level of physical activity, a clinician can develop a program which progresses through foundational movements into advanced movements which resemble free flowing dance movements, or tailor the program to introduce breathing with occupational/sport specific activities. In the realm of athletic training, patients may present with breathing dysfunction caused by a variety of factors such as compensatory movements in the kinetic chain, diaphragmatic dysfunction, thoracic sprain or strain, rib dysfunction, heightened levels of anxiety or stress, or faulty breathing mechanics. Inherently, breathing dysfunction can result in a negative impact on health-related quality of life for patients.

\section{Applying A Patient-Centered Lens To Care}

An important part of effectively providing patient-centered care is understanding more about the patient than just the condition. This understanding must dive deeper than a physical wellness understanding of the individual. There are seven dimensions which are key to understanding the holistic wellbeing of a patient. These dimensions include: social, emotional, spiritual, environmental, occupational, intellectual, and physical. ${ }^{8}$ When providing care to a patient presenting with a form of breathing dysfunction, that can be defined as a breathing disorder in which respiration patterns change due to chronic factors resulting in dyspnea and other symptoms, a holistic approach must be employed to identify the contributing factor(s). Examples of how a condition can impact the seven dimensions of wellness can be found in Table 2. This is not intended to be an exhaustive list of

Table 2. Implications of Impairment on the Seven Dimensions of Wellness.

\begin{tabular}{ll}
\hline Dimension & Implications \\
\hline Social & $\begin{array}{l}\text { External pressure to continue occupational/sport duties; change or } \\
\text { loss of social identity }\end{array}$ \\
\hline Emotional & $\begin{array}{l}\text { Internal pressure to continue occupational/sport duties; internal loss } \\
\text { of social identity; stress and/or anxiety associated with pain during } \\
\text { physical activity/breathing }\end{array}$ \\
\hline Spiritual & $\begin{array}{l}\text { Dependent on the patient's spiritual beliefs tai chi can support, } \\
\text { conflict, or be indifferent towards patient's spiritual health }\end{array}$ \\
\hline Environmental & $\begin{array}{l}\text { Increased number of provider visits can increase the impact of on } \\
\text { environmental factors (pollution, healthcare system, economic, etc.) }\end{array}$ \\
\hline Occupational & $\begin{array}{l}\text { Pressure to continue meeting the organizational expectations of } \\
\text { occupation/sport activity during and after injury }\end{array}$ \\
\hline Intellectual & $\begin{array}{l}\text { Patient education and cultural understanding of impairment is vital } \\
\text { for treatment and success of interventions }\end{array}$ \\
\hline Physical & Patient may experience pain with activities of daily living, pain with \\
occupational/sport specific functions, or decreased level of function
\end{tabular}


holistic factors to consider, but is designed to help a clinician understand the frame of mind necessary to apply well-rounded patient care and extent of impairment on these domains. A patient who presents with thoracic, musculoskeletal pain with breathing during exercise and increased levels of stress and anxiety during physical activity many be a patient case worth considering the use of tai chi as a therapeutic intervention. When considering social and emotional wellness, a patient could be experiencing internal or external pressure to perform at a high level. Of the examples provided in Table 2, some of these factors can result in heightened anxiety and stress, which may result in physiologic changes like increased heart rate and respirations. These changes can alter the intricate function of the respiratory system.

\section{CONCLUSION}

As a $\mathrm{ClH}$ technique, tai chi can be incorporated into a patient's plan of care in conjunction with other interventions. As the current literature indicates, ${ }^{3-5}$ patient outcomes related to mental health and physical impairment significantly improve regardless of the programming parameters for tai chi intervention. Due to the fact that guidelines are not specific, a clinician should work with the patient to set a plan of care which best suits the patient's availability, needs, and preferences. As a clinician it is viable to provide patients with options when establishing a plan of care which aims to address the goals the patient seeks to accomplish while receiving care. In order to best address patient needs and goals, a clinician must not only understand the clinical relevance of all considered interventions, but also recognize the impact a condition and intervention will have on the seven dimensions of patient wellness.

\section{REFERENCES}

1. National Center for Complementary and Integrative Health. U.S. Department of
Health and Human Services - National Institutes of Health. https://nccih.nih.gov/research/camonpu bmed/background.htm. Updated Sept 24, 2017. Access Date: June 6, 2018.

2. Clarke TC, Black LI, Stussman BJ, et al. Trends in the use of complementary health approaches among adults: United States, 2002-2012. Natl Health Stat Report. 2015;79:1-15.

3. Bu B, Haijun $H$, Yong $L$, et al. Effects of martial arts on health status: A systematic review. J Evid-Based Med. 2010;3:205219. https://doi.org/10.1111/i.17565391.2010.01107.x

4. Sharma M, Haider T. Tai Chi as an Alternative and Complimentary Therapy for Anxiety: A Systematic Review. J EvidBased Complimentary \& Altern Med. 2015;20(2):143-153. https://doi.org/10.1177/2156587214 $\underline{561327}$

5. Wang F, Othelia Lee EK, Wu T, et al. The effects of tai chi on depression, anxiety, and psychological well-being: $A$ systematic review and meta-analysis. Intl J Bev Med. 2014; 21:605-617. https://doi.org/10.1007/s1 2529-0139351-9

6. Xiong KY, He H, Ni GX. Effect of skill level on cardiorespiratory and metabolic responses during Tai Chi training. Eur J Sport Sci. 2013;13(4):386-391. https://doi.org/10.1080/17461391.20 $\underline{11.635706}$

7. Polkey MI, Qiu ZH, Zhou L, et al. Tai chi and pulmonary rehabilitation compared for treatment-naive patients with COPD: A randomized controlled trial. Chest. 2018;153(5): $1116-24$.

\footnotetext{
Clinical Practice in Athletic Training
} Volume 1 - Issue 2 - October 2018 
https://doi.org/10.1016/i.chest.2018.0

$\underline{1.053}$

8. Lyon, K. The Seven dimensions of wellness. American Medical Student Association. https://www.amsa.org/the-sevendimensions-of-wellness/. Updated July 8 , 2015. Access Date: August 25, 2018.

9. Boulding R, Stacey R, Niven R, Fowler SJ. Dysfunctional breathing: A review of the literature and proposal for classification. Eur Respir Rev. 2016;25:287-94. https://doi.org/10.1183/16000617.00 88-2015. 